\title{
Mística ecológica para uma caminhada ecopedagógica
}

\author{
Luiz Síveres *
}

\begin{abstract}
Resumo
A mística ecológica está sendo compreendida como uma disposição vinculante de sujeitos que estão fazendo a experiência do mistério, que pode ser vivenciada na interioridade da própria pessoa, na vinculação com os outros, na conexão com o meio ambiente ou na contemplação do sagrado. A proposição deste trabalho, porém, é perceber como esta reflexão e esta prática se dariam na conectividade com a natureza, optando-se pela sua materialização por meio de um processo pedagógico que privilegia a subjetividade feminina, principalmente pelo exercício das virtudes da hospitalidade, da responsabilidade e do cuidado com o planeta. A inspiração deste texto teve como referência um comprometimento do autor com a realidade ecológica, mas que veio se apoiar no documento do Papa Francisco: Laudato Si', que propõe o cuidado da casa comum. Além disso, uma entrevista com a poetisa Adélia Prado, da qual foram extraídas algumas epígrafes, foi de fundamental importância para a formatação desta temática. Por isso, o objetivo deste artigo é despertar para uma mística ecológica, que mediada por uma caminhada ecopedagógica, possa contribuir com o cuidado da casa comum, que é o planeta terra.
\end{abstract}

Palavras-chave: ecologia, ecopedagogia, mística.

\section{Ecological mystic for an ecopedagogical direction}

\begin{abstract}
Ecological mystic is understood as a binding disposition of subjects within the experience of mystery, which can be lived out within a person, in bonds to others, in connection with the environment, or in contemplation of the sacred. The aim of this study, however, is to perceive how this reflection and this practice would work in connectedness with nature, opting to bring it about through a pedagogical process that gives priority to feminine subjectivity, especially through the exercise of the virtues of hospitality, of responsibility, and of care for the planet. The inspiration for this text has the commitment of the author to ecological reality as a reference, but came to find support in the document of Pope Francis, Laudato Si', which proposes care for our common home. In addition, an interview with the poet Adélia Prado, from which some motifs were taken, was of fundamental importance in shaping this theme. Thus, the aim of this article is to awaken to an ecological mystic, which, mediated by an ecopedagogical movement, can contribute to care for our common home, which is the planet Earth.
\end{abstract}

Keywords: ecology, ecopedagogy, mystic.

\footnotetext{
* Professor e Coordenador do Programa de Pós-Graduação Stricto Sensu em Educação da Universidade Católica de Brasília.E-mail: luiz@ucb.br; luiz.siveres@catolica.edu.br
} 


\section{Introdução}

A história da humanidade, de modo especial no contexto ocidental, está potencializando uma ação pendular que se inclina cada vez mais para o lado da racionalidade. Pode-se perceber, no entanto, que esta tendência trouxe enormes benefícios à sociedade contemporânea, mas começa a exigir uma ressignificação, no sentido de incorporar a este movimento, de modo especial, a dinâmica da espiritualidade. Esta proposta está ancorada na sugestão de Morin (2005), que indica para uma simbiose entre a racionalidade e a espiritualidade, ou uma simbiose entre a racionalidade universal e o componente místico do universalismo ético.

Independentemente de qualquer profissão de fé ou de qualquer agregação religiosa, a espiritualidade será compreendida como um elemento constitutivo da condição humana e, por isso, está sendo proposta por meio da prática e do conceito de mística, que é um constante processo de iniciação e interação com o mistério, que pode ser exercitado tanto na relação subjetiva, na conexão intersubjetiva, na interação com a natureza e na contemplação do sagrado.

A mística é, portanto, uma dinâmica integrante e integradora da condição humana e é influenciada pelos movimentos culturais e interage nos processos históricos, articulando o aspecto material e espiritual, o atributo racional e sensível, bem como o caráter da imanência e da transcendência. Numa sociedade extremamente materialista, racionalista e hedonista, a mística aponta para a necessidade de se repensar o projeto civilizatório e vivenciar com maior intensidade os aspectos espirituais, relacionais e transcendentais.

Nesta conjugação entre o real e o espiritual encontra-se a proposta de realização integral do ser humano, que segundo Lima Vaz (2009), se dá de forma privilegiada pelo exercício da política e pela experiência mística, contribuindo para uma abertura para o Outro e uma aliança com o Sagrado, respectivamente. Neste contexto, a mística é compreendida pelo autor por meio de uma relação tridimensional que incorpora o sujeito da experiência (místico), o processo de iniciação (mística) e a relação com o seu objeto (mistério).

A opção por este direcionamento pode ser entendida porque o movimento ecológico está ocupando um espaço importante na definição de políticas públicas, no encaminhamento de diretrizes governamentais e na proposição de projetos institucionais. O sucesso destas iniciativas, dentre outras, depende essencialmente de uma proposição política, mas de modo especial, de uma experiência mística. Neste sentido, 
a mística ecológica será compreendida como um exercício que busca estabelecer uma aliança, de modo especial, com o meio ambiente.

As exigências de mudança em relação ao meio ambiente e a necessidade de um novo posicionamento na definição de um planeta mais saudável dependem, neste momento, das opções que a humanidade irá fazer no decurso nos próximos anos. Para isso, torna-se necessário um procedimento que contribua com a moldagem de novos comportamentos que ajudem a cultivar virtudes, maturar valores e desenvolver a ética, características necessárias para o exercício de uma mística ecológica.

Para o desenvolvimento de tal proposta, além da contribuição nuclear da família e da diversidade dos agrupamentos sociais, a comunidade escolar estaria sendo convocada para projetar uma educação que pudesse desenvolver estes princípios, objetivando fortalecer um processo educativo nas pegadas de um caminho ecopedagógigo, que seria a tomada de consciência de sua responsabilidade ética e, consequentemente, de uma prática responsável de cuidado do planeta.

Esta sugestão depende, essencialmente, do entendimento de que será necessário inaugurar uma nova consciência, sugerida pelo Papa Francisco, "de uma origem comum, de uma recíproca pertença e de um futuro partilhado por todos" (2015, p. 121). A percepção temporal de que a humanidade não se restringe aos desejos e necessidades do tempo presente, mas que a mesma é herdeira de uma história e que o futuro dependerá, em grande parte, dos encaminhamentos que serão dados pela sociedade contemporânea, aponta para a urgência de uma atitude responsável para estabelecer novas conexões com a natureza.

\section{Mística ecológica}

\section{O mundo está cinzento.}

A produção editorial e cinematográfica foi movimentada, nos últimos anos, pela obra: Cinquenta tons de cinza. Esta proposta literária e artística, além de muitos outros aspectos, está revelando uma disposição cultural no sentido de reforçar uma tendência que prioriza o pornográfico em detrimento do erótico, ou a satisfação sexual em detrimento de um amor relacional. Portanto, como a pornografia entra muito mais no aspecto comercial e o erótico no relacional, estaria se transferindo a dinâmica da vida para o esgotamento das potencialidades de cores mais vivas e mais fortes e avolumando-se a repetição da mesma cor, isto é, a tonalidade cinza que expressaria a referência única e exclusiva das disposições entre produção e consumo.

Além desta tonalidade que está afetando a característica cultural, Adélia Prado 
aponta para esta realidade cinza, fazendo referência ao conjunto das pessoas, mas destacando a figura dos jovens, porque perderam a capacidade de amar, abandonaram a luta por ideais e se ausentaram de projetos que pudessem contribuir com a construção de uma sociedade mais sustentável. A predominância destas características, dentre outros procedimentos, está afetando o sentido existencial da humanidade, de modo especial a juventude, porque pela sua adesão a produtos ou processos que proporcionam uma satisfação imediata, está tornando a sua vida ainda mais cinzenta, isto é, mais vazia e mais sem sentido.

Esta tendência cultural e pessoal pode ser percebida, ainda, no movimento ecológico e, para isso, é oportuno inteirar-se de uma compreensão de mundo e recuperar o pronunciamento do Papa Francisco, no sentido de que "damo-nos conta de que este nível de intervenção humana, muitas vezes ao serviço do sistema financeiro e do consumismo, faz com que esta terra onde vivemos se torne realmente menos rica e bela, cada vez mais limitada e cinzenta" (2015, p. 27). Tal afirmação revela que o planeta está cada vez mais cinzento porque existe uma negligência para com a natureza, principalmente pela devastadora extração dos bens naturais e pela avassaladora poluição do meio ambiente, aspectos resultantes do atual modelo de desenvolvimento.

Por meio destas manifestações culturais, pessoais e ambientais é necessário reconhecer a veracidade da intuição da poetisa, no sentido de afirmar de que o mundo está cinzento. O objetivo desta reflexão não é fazer, porém, uma interpretação das cores, mas apenas capturar uma percepção que estaria se revelando por meio destas expressões, bem como pelas demais características sociais, pelos distintos aspectos da condição humana e pela diversidade de atributos ambientais.

Como proceder diante desta tonalidade cinza? Em situações similares a busca para superar um estágio desolador foi a crença na proposta e no posicionamento das instituições, mas neste momento histórico os agrupamentos institucionais, seja no seu núcleo familiar, na representação política ou até na expressão religiosa, estão sofrendo de uma descrença em relação à sua legitimidade. Portanto, com base nesta percepção, a desconfiança nas instituições está se transformando, infelizmente, numa expressão de descontentamento pessoal e de desencanto social, fatores que revelam ainda mais a tonalidade cinza da civilização contemporânea.

Por outro lado, a busca para superar este contexto desanimador foi vinculado ao exercício de experiências espirituais. A compreensão que se tem sobre as mesmas, porém, é que a espiritualidade continua atrelada às doutrinas, confinada às instituições ou vinculada aos ritos, e continua ainda, com posturas dogmáticas e pressupostos doutrinários sugeridos pelas religiões, em vez de se converter numa dinâmica existencial 
do cotidiano que incorpore o movimento da cultura e possa refletir a realidade histórica atual.

Este procedimento revela, portanto, que estamos cada vez mais descoloridos ou desbotados, seja pelo desencanto com as utopias sociais, pelo desânimo existencial ou pela desconexão com o meio ambiente. Tais características, típicas da realidade atual, poderiam ser acrescidas de muitas outras que revelam a ruptura de uma aliança consigo mesmo e com os outros, com o transcendente e com o meio ambiente.

Por esta razão, uma das possibilidades para reverter este quadro seria uma mística que pudesse questionar este modelo social, demarcado pela proeminência da materialidade e da individualidade e que estaria gestando uma sociedade cada vez mais egoísta e egocentrada, apesar dos recursos disponíveis e das oportunidades disponibilizadas pelo processo de desenvolvimento econômico e social.

Estaria se sugerindo, ainda, uma mística que pudesse questionar a primazia dada à racionalidade instrumental ou ao ativismo comercial, fatores predominantes no contexto contemporâneo, porque uma razão que não incorpora uma dinâmica emocional a um movimento transformador redundaria numa irracionalidade. Daí a importância em articular uma relação complementar entre o espiritual e o intelectual, bem como, resgatar experiências que estão sinalizando para esta interatividade.

É recomendado retomar, também, toda uma problemática vinculada à crise ecológica, que segundo Leff (2001), é resultado da fratura da razão moderna. E tal racionalidade tem o poder, ainda, de separar a economia da ecologia, desvincular o desenvolvimento técnico do envolvimento ético, e afastar a proeminência da instrumentalidade em detrimento da sua finalidade. Diante disso o autor sugere a retomada de uma racionalidade ambiental que seja capaz de gerar um novo projeto civilizatório, pautado na reaproximação com a natureza, na ressignificação das identidades pessoais e culturais, e na renovação dos valores éticos da ambientalidade.

$\mathrm{Na}$ percepção desta realidade está sendo sugerida, portanto, uma mística que seja capaz de potencializar a energia do coração, que em sintonia com a razão, fosse capaz de potencializar uma sinergia operativa para estabelecer uma sinfonia com a dinâmica social, ambiental e transcendental. Seria uma mística vinculada à cultura da vida e conectada com o mundo natural, uma mística consciente que tem consequências para a vida pessoal e social, uma mística capaz de proporcionar um encontro, um diálogo e uma aliança com o transcendente, com os outros e com o meio ambiente.

No caso específico desta aliança com a dimensão ecológica é oportuno recuperar a proposta de Capra (2004), no sentido de que a consciência ecológica deveria 
estar vinculada a uma prática espiritual. E com base nesta percepção, o autor afirma que o experimento dos astronautas, que ao observarem o planeta terra como um balão azul e branco, puderam fazê-lo a partir de uma experiência mística que mudou a sua relação com a terra. Neste caso, a mística não foi apenas uma mudança de percepção do planeta visto do alto, mas a mudança de compreensão da terra vista a partir de uma consciência espiritual.

A mística ecológica seria, portanto, a compreensão da condição humana marcada por uma aliança consigo mesmo e com os outros, com a natureza e com o transcendente. Porém, a experiência original da humanidade é descrita, justamente, pelo rompimento desta aliança por meio do afastamento do homem de Deus no paraíso, pela morte de Abel por seu irmão Caim, e pela destruição do planeta através do dilúvio. Percebe-se, portanto, que há uma correlação entre estes distintos níveis de rompimento da aliança, seja com a divindade, com a fraternidade e com a planetaridade, respectivamente.

No contexto da narrativa do livro do Gênesis, após o rompimento destas alianças, é proposto a Noé, como representante da condição humana, sair da arca e contemplar o arco. Neste caso, a saída da arca e o reconhecimento do arco simboliza a aliança que se estabelece, novamente, com a divindade, com a fraternidade e com a planetaridade. Assim, o arco-íris, como símbolo da aliança, se expressa num conjunto de cores, revelando a superação da tonalidade cinza e sugerindo a vivacidade das cores do arco-da-aliança.

Esta compreensão mais religiosa permeou a história da humanidade, mas de forma renovadora, e no contexto mais científico, Stengers e Prigogine (1991) propõem uma nova aliança, no sentido de compreender o ser humano, não através de uma posição autocentrada e separada da natureza, mas muito mais num posicionamento auto organizado e em comunicação constante com a natureza. Acoplada a esta compreensão se estaria sugerindo uma outra maneira de fazer ciência, não mais desconectada e descontextualizada, mas atrelada aos distintos saberes e às diversas possibilidades científicas. Ainda, segundo a proposta dos autores, estaríamos vivendo um tempo oportuno para inaugurar novas alianças entre os humanos, outras formas de viver em sociedade e outras maneiras de se vincular com a natureza.

No contexto mais recente, a proposta da aliança foi introduzida na Carta da Terra (BOFF, 2012). O referido texto indica para um conjunto de princípios que estão distribuídos pelos temas que abordam o respeito e o cuidado da comunidade humana, a integridade ecológica, a justiça social e econômica, a democracia, a não violência e 
a paz. No preâmbulo do texto é apresentada a Terra como nosso lar, e para que a convivência neste espaço terrenal seja saudável e sustentável, é sugerido um espírito de solidariedade, um projeto de responsabilidade universal e, principalmente, o desafio de projetar para o futuro da humanidade uma aliança global, que seja capaz de cuidar da Terra, bem como, cuidar uns dos outros.

A vida humana e o meio ambiente, quando contemplados de forma isolada geram uma crise, mas, quando são compreendidos de forma complementar, são capazes de potencializar uma ética da coexistência. Para desenvolver esta ética, de acordo com Cirne (2013), é necessário estabelecer conexões entre os conhecimentos, um diálogo entre os saberes e um novo relacionamento com o mundo natural. Assim, o ser humano, segundo o autor, estaria sendo convocado a estar numa íntima conexão com todos os demais seres e numa disposição dialogal com todas as formas de conhecimento, constituindo um tempo e um espaço de coexistência.

A mística ecológica seria, portanto, a superação de um mundo cinzento, no qual as relações pessoais, sociais e ambientais estariam sendo fragmentadas pelas ocupações e preocupações do cotidiano, pelos projetos de desenvolvimento econômico e social e pela dinâmica acumuladora e destruidora da natureza. E a possibilidade de reversão desta tonalidade cinza e a proposição de um mundo mais colorido poderiam ser feitos de distintas maneiras, mas aqui estaria se propondo a vivência de uma aliança na sua individualidade e sociabilidade, a experiência de uma nova aliança com a ambientalidade, bem como, a convivência com a divindade por meio do arco-da-aliança. Esta proposta de uma mística ecológica, pautada na dinâmica da aliança, está sendo sugerida como sinalizador da caminhada ecopedagógica.

\section{Caminhada ecopedagógica}

Está faltando a presença feminina no mundo.

A caminhada ecopedagógica pode ser percorrida por diversos sujeitos, realizada em distintos territórios e feita em múltiplas temporalidades. Neste momento histórico, caracterizado pela tonalidade cinza, é oportuno recuperar a importância da subjetividade feminina, simbologia assumida pelo Papa Francisco (2015) ao propor que a casa comum pode ser comparada a uma irmã, com quem se compartilha a existência, ou com a mãe que assume a missão acolhedora. Além da figura da irmã e da mãe será incorporado, ao sujeito feminino, o arquétipo da mulher. 


\subsection{Subjetividade feminina}

A subjetividade feminina é uma característica da condição humana, mas a mesma será caracterizada pela figura da mãe, da irmã e da mulher, como uma tentativa de recuperar as energias próprias destas representações, bem como, uma busca reveladora da necessidade de sua presença neste contexto histórico, porque segundo Adélia Prado, está faltando a presença feminina no mundo. A dinâmica feminina sempre existiu na história da humanidade, mas no contexto atual, ela está se tornando cada vez mais necessária e, portanto, mais esperada e mais valorizada.

Esta proposição está ancorada na percepção de um contexto histórico que se fortaleceu, nos últimos séculos, pelo biocentrismo, na medida em que os seres vivos foram reinando como senhores absolutos, pelo antropocentrismo, na medida em que o domínio do universo foi se dando pelo ser humano, e pelo falocentrismo, na medida em que a dominação do gênero masculino foi predominante. Estas tendências trouxeram muitas melhorias, mas ao mesmo tempo, continuam impondo limites que podem ser percebidos pela exposição desta tonalidade acinzentada.

As tendências acima mencionadas, dentre outras, são características da cultura contemporânea que se expressam de maneira evidenciada pelo modelo social mais masculino, cuja expressividade se dá pela dinâmica tanto paternal, quanto patriarcal e patronal. Por outro lado, se estaria propondo uma dinâmica que pudesse ser fecundada pela expressão do feminino, por meio da representatividade tanto do maternal, quanto do matriarcal e do matricial.

Esta nova fecundação, segundo Gutiérrez e Prado, estaria sendo gestada "com o respeito e a cooperação; com a harmonia biológica e cultural; com a confiança e o prazer da convivência, com o afeto, a doçura e o amor". Tal fecundação se daria, ainda, "com a participação, a flexibilidade e a solidariedade; com a admiração pela beleza e o mistério da vida; com a união e a veneração pela natureza; com criatividade, o conhecimento intuitivo e a dimensão espiritual do ser humano" (2013, p. 91). Embora estas características sejam próprias do ser humano, a subjetividade feminina teria a possibilidade e a responsabilidade de vivenciá-las com mais expressividade no contexto atual.

Assim, a caminhada ecopedagógica, contando com a contribuição da subjetividade feminina, se transformaria num percurso pedagógico que poderia colaborar com um processo educativo mais holístico, sustentável e ecológico. Tal percurso estaria pautado, como visto anteriormente, numa aliança que se estabelece com o transcendente, num diálogo que se fortalece na relação com o outro, e numa coexistência que acontece na conexão com o meio ambiente. 
Com o objetivo de potencializar esta possibilidade anunciada, pretende-se compreender esta dinâmica como uma energia que se revela na natureza, mas principalmente, na natureza humana, por meio da subjetividade feminina manifestada pela figura da mãe, da irmã e da mulher. Esta disposição pode ser identificada por meio de diversas expressões, mas pretende-se vincular à subjetividade feminina da mãe a virtude da hospitalidade, da irmã a fraternidade e da mulher ao cuidado com o planeta.

\subsubsection{O arquétipo da mãe e a virtude da hospitalidade}

Ser mãe é mais do que desempenhar um papel, exercer uma função ou representar um status social. Ser mãe é um jeito de ser, uma maneira de pensar e uma forma de agir que integra, de forma harmoniosa, o espírito, o pensamento e a corporalidade. Este modelo da maternidade é universal porque todos os seres humanos foram acolhidos neste útero e no acolhimento deste arquétipo universal nos tornamos humanos e, como tais, peregrinamos pelos caminhos da história. E nesta jornada fazemos, cotidianamente, a experiência da hospitalidade, que no fundo, é a expressão circunstancial da maternidade.

É possível entender que desde a compreensão grega do mito da hospitalidade, narrado pelo poeta romano Públio Ovídio, logo no início do primeiro milênio, pode-se perceber um encontro de pessoas, que por um lado exercitam o acolhimento e, por outro, expressam a necessidade de serem acolhidas. Com base nesta narrativa, Boff (2005) conclui que a hospitalidade, apesar de se dar na relação, define-se sempre a partir do outro, seja pelos seus desejos ou pelas suas necessidades, justamente para cumprir com um projeto ético.

A hospitalidade pode ser entendida, na continuidade desta proposta, de acordo com Síveres e Melo (2012), como um encontro interpessoal demarcado pela atitude de acolhimento do Outro, objetivando transformar o mundo num lugar mais humano, configurado como um lugar de hospitalidade. Tal proposta não se resume a um elenco de atividades, mas se transforma num princípio ético, porque de acordo com Derrida, "a hospitalidade é a própria cultura, e não uma ética entre outras. A ética é a hospitalidade" (1997, p. 47). Neste sentido, tanto a vida humana quanto a natural precisam ser acolhidas como um projeto ético.

A materialidade deste princípio ético da hospitalidade, dentre inúmeras implicações, pode ser depreendida da proposta de Kant (1995), que entendia a hospitalidade como um direito de todo o cidadão e, portanto, tornar-se-ia um dos direitos mais importantes no contexto da globalização. Tal procedimento tem seus contornos 
ativados, atualmente, por meio dos refugiados individuais e coletivos, pelos migrantes pessoais e culturais, todos eles deixando seus territórios e buscando países que os possam acolher. Nesta dinâmica entra em jogo, justamente, o direito da hospitalidade de todo o cidadão e o dever do estado para inaugurar uma cidadania universal.

Vinculada a esta disposição de cidadania, o texto do Papa Francisco (2015), logo no início do documento sugere que a terra, como a casa comum, pode ser comparada a uma mãe porque desempenha o papel de acolher a humanidade em seus braços, mas logo na sequência indica as situações que estão descaracterizando esta relação de acolhimento. Segundo este entendimento, se estaria desfigurando a função da maternidade impressa nesta relação e sugerindo a necessidade de uma conversão ecológica com o objetivo de retomar a experiência original da maternidade.

A hospitalidade torna-se, portanto, no contexto histórico atual, a virtude por excelência da maternidade. É na condição de mãe que a energia feminina tem a capacidade de acolher a vida que foi semeada, a história que está sendo construída, os bens disponibilizados pela natureza, e os dons doados pela divindade. A figura da mãe, por meio do acolhimento, caracteriza-se por uma convocação para conceituar e vivenciar uma ecologia integral que teria, nesta abordagem, a característica da hospitalidade.

\subsubsection{A figura da irmã e a virtude da responsabilidade}

A casa comum, a terra, ainda é comparada pelo Papa Francisco (2015), à figura da irmã, porque ela é capaz de compartilhar a sua existência. Para exemplificar esta atitude é retomado o exemplo de São Francisco, porque com todos e com tudo era capaz de estabelecer uma relação de irmandade, destacando-se o modelo de fraternidade universal por meio das atitudes de cuidar e cultivar, e promovendo a solidariedade global, geracional e universal. Inúmeras são as possibilidades para implementar tal proposta, mas aqui se está sugerido o princípio da responsabilidade, que se caracteriza como uma virtude da irmandade no contexto contemporâneo.

A responsabilidade pessoal e social, mas principalmente ambiental é um princípio proposto por Hans Jonas, que o coloca no patamar da ética. Segundo o autor, "Isso impõe à ética, pela enormidade de suas forças, uma nova dimensão, nunca antes sonhada, de responsabilidade" (2006, p. 39). A responsabilidade nem sempre esteve contemplada pela compreensão e pela experiência ética, mas o autor sugere que, na conjuntura atual, a ética precisaria estar imbuída do princípio da responsabilidade, principalmente pela sua vinculação com a natureza.

Segundo a compreensão de Jonas (2006), existe uma agressão intensificada so- 
bre a natureza, cuja mudança vai depender de uma ética pautada na responsabilidade. Esta ética, segundo o autor, é de "segurar as rédeas desse progresso galopante" (2006, p. 349), promovido de forma exponencial pelo desenvolvimento tecnológico. Esta proposição tem como referencial, no entanto, não contradizer o avanço das tecnologias, mas questionar a função dominadora e destruidora da natureza, podendo comprometer o futuro da humanidade e do planeta terra.

A responsabilidade como uma virtude da irmandade se expressa como um princípio ético, que segundo Jonas, não é tanto de natureza objetiva, mas muito mais de uma disposição subjetiva. Segundo o autor, este "novo imperativo clama por outra coerência: não a do ato consigo mesmo, mas a dos seus efeitos finais para a continuidade da atividade humana no futuro" (2006, p. 48). A proposição deste princípio se transforma, inicialmente, num questionamento sobre a responsabilidade que o ser humano tem na sua relação com o meio ambiente e, posteriormente, num exercício constante de ser irmão ou irmã da natureza, até para garantir o futuro da humanidade.

Esta proposta é retomada pelo Papa Francisco ao afirmar que "o imenso crescimento tecnológico não foi acompanhado por um desenvolvimento do ser humano quanto à responsabilidade, aos valores, à consciência" (2015, p. 67). Esta convocação pode ser pautada, também, num direcionamento ético porque se constitui numa tomada de consciência no horizonte dos valores, destacando-se o princípio da responsabilidade. Assim, a proposição mais significativa desta caminhada está sendo ordenada por meio da responsabilidade, que pelo exercício da fraternidade poderia inaugurar uma fraternidade universal.

\subsubsection{O modelo da mulher e a virtude do cuidado}

Além da figura da mãe e da irmã, está sendo proposto o modelo da mulher. Para isto poderíamos retomar o exemplo de algumas mulheres que marcaram a história contemporânea, tais como Hannah Arendt, Simone Weil e Edith Stein, que partiram de um pressuposto religioso, navegaram pelo oceano da Filosofia, mas aportaram no mundo acadêmico, na realidade do trabalho e no contexto da mística, respectivamente. Com essas características, estas mulheres se consolidaram pela expressão do seu pensamento e marcaram profundamente o século passado.

No contexto brasileiro, poderíamos recordar a figura marcante de Elis Regina e Chiquinha Gonzaga no campo da música, Zilda Arns e Irmã Dulce na promoção dos mais pobres, Cora Coralina e Raquel de Queiroz na poesia e literatura. É oportuno reconhecer, no entanto, que cada uma dessas mulheres, seja no seu contexto histó- 
rico, na sua compreensão de mundo ou na sua expressão cultural, buscaram revelar um perfil da sua condição feminina. Além destas, inúmeras mulheres poderiam ser mencionadas pelo seu compromisso político, pela sua ocupação profissional ou pela sua dedicação familiar, mas deseja-se destacar, no conjunto destas características, uma preocupação com a ética do cuidado.

O princípio do cuidado foi amplamente discutido por Heidegger (2012), que o compreendia tanto pelo exercício da cura quanto pela prática do cuidado. Para o autor, a "cura é sempre ocupação e preocupação [...], isto é, um ente já projetado em suas possibilidades como ente a ser tratado na ocupação ou a ser cuidado em seu ser na preocupação" (2012, p. 261). Esta proposta define o ser humano como um ser do cuidado, principalmente quando está ocupado consigo mesmo, isto é, na medida em que está buscando o modo-de-ser e quando está preocupado em ser-no-mundo, no horizonte de suas relações com as demais realidades. Em suma, o ser humano é, por natureza, um ser do cuidado quando está sendo e quando está convivendo.

Considerando que o ser humano é um ser do cuidado, Boff (2003) sugere a passagem de um paradigma-conquista para um paradigma-cuidado, caracterizado pela condição humana que permite o aflorar da razão e da emoção, da serenidade e da amorosidade, da liberdade e da responsabilidade, características que em sincronia assumem a função de criação, de prevenção e de regeneração da vida sobre o planeta terra.

Compreendendo, no entanto, que a essência do ser humano está pautada no cuidado, o mesmo se caracteriza como um princípio ético. Portanto, a ética do cuidado, segundo Boff (2003), é a atitude de fazer tudo com cuidado, revelando a essência do ser humano e a potencialidade de tudo fazer bem. Neste sentido, o cuidado se torna um princípio ético fundamental, de modo específico para um projeto civilizatório que deseja cuidar dos seres humanos e do meio ambiente.

O cuidado é, também, uma temática transversal do documento Laudato Si, de maneira explícita ao propor a exigência de uma mudança de estilo de vida, não mais pautado na produção e no consumo, mas preocupado com o cuidado da criação. Portanto, de acordo com o Papa Francisco, "a atitude basilar de se auto-transcender, rompendo com a consciência isolada e a auto-referencialidade, é a raiz que possibilita todo o cuidado dos outros e do meio ambiente" (2015, p. 124).

Por esta razão, o cuidado não é apenas uma atitude individual, mas exige um empenho comunitário e um projeto social que possibilita cuidar da humanidade e da natureza e, por isso, o Papa Francisco argumenta que "O cuidado da natureza faz parte de um estilo de vida que implica capacidade de viver juntos e em comunhão" (2015, p. 
133). O projeto de viver junto e em comunhão torna-se, talvez, o maior desafio deste século e, dada a importância desta proposta, a ética do cuidado é recomendada para inaugurar e desenvolver uma cultura do cuidado.

Enfim, a contribuição dos sujeitos femininos, caracterizados pelo arquétipo da mãe, do protótipo da irmã e do modelo da mulher, são proposições que buscam regenerar uma sociedade estruturada na virtude da hospitalidade, da responsabilidade e do cuidado, respectivamente, e tem por objetivo contribuir com a compreensão de uma ecologia integral, com a proposição de uma fraternidade universal e com a efetivação de uma cultura do cuidado.

Tendo como referência estes símbolos, todos os processos educacionais deveriam contribuir para desenvolver, dentre outros princípios éticos, a hospitalidade, no sentido de compreender que todo ser humano tem o direito de ser acolhido, da responsabilidade, no entendimento de que todos pertencem à casa comum, e do cuidado, pelo procedimento de que é necessário cultivar as virtudes que contribuem para o exercício de uma cidadania ecológica. Tais virtudes, além de expressarem a condição do sujeito feminino, precisariam estar sendo incorporadas e vivenciadas num processo pedagógico.

\subsection{Processo pedagógico}

Além de sugerir a subjetividade feminina, por meio das expressões éticas descritas, está se propondo um processo pedagógico que poderia contribuir com uma conexão mais saudável e sustentável com o meio ambiente. Para se colocar nesta caminhada, segundo o Papa Francisco (2015), é necessária uma mística, que é uma energia que parte do interior da pessoa humana, mas que ressoa nas relações comunitárias e sociais e impacta na natureza. Mas ao mesmo tempo retorna da natureza para a realidade social e para a condição humana, estabelecendo uma circularidade de energias. Assim, a mística é uma experiência relacional que se estabelece no interior de todo ser humano, na sua relação com os outros, com a natureza e com o transcendente.

Esta forma integradora dos distintos aspectos da condição humana pode ser contemplada por um percurso, que teria por sua vez a função de predispor a humanidade, segundo o Papa Francisco (2015), para um salto no Mistério. Apesar das dinâmicas pessoais e sociais desnudarem todas as formas misteriosas, este procedimento poderia colaborar para recuperar esta dimensão mística na conexão com o meio ambiente.

$\mathrm{Na}$ medida em que o desempenho educativo se dedicar ao desenvolvimento 
destes comportamentos, dentre outros que são de importância reconhecida, o exercício da docência, segundo o Papa Francisco (2015), poderia restituir aos educadores o sentimento de sua dignidade, aprofundar a experiência existencial e dar um sentido à sua passagem por este mundo, neste período histórico e neste contexto socioambiental.

Uma proposição posterior será a de eleger uma série de prioridades que possam contribuir com esta consciência de cidadania ecológica. Dentre inúmeras iniciativas, a educação poderia se tornar um caminho apropriado porque ajudaria a conduzir a humanidade, segundo o Papa Francisco (2015), para um equilíbrio ecológico no qual estão articuladas as dimensões pessoais, sociais e espirituais. Tal procedimento poderia ser implementado em todos os níveis educativos, porém, respeitando-se as características próprias de cada segmento social.

Este processo caracteriza-se, portanto, por uma iniciação ao mistério e, segundo o Papa Francisco, "A educação ambiental deveria predispor-nos para dar este salto para o Mistério, do qual uma ética ecológica recebe o seu sentido mais profundo" (2015, p. 124). Para se alinhar a esta proposição, se estaria sugerindo a continuidade da reflexão anterior, com a retomada da subjetividade feminina por meio do protótipo da mulher Samaritana, que se encontra com Jesus no poço de Jacó.

O referido fato é relatado pelo evangelista João (4,5-30), e o mesmo pode ser compreendido de distintas formas e com base em diferentes interpretações, mas não é objetivo deste trabalho fazer uma exegese bíblica e nem tampouco uma hermenêutica textual, mas perceber que os escritos sagrados são, de acordo com Corbí (2010), testemunhas dos mestres do espírito. Uma dessas características pode ser percebida pela proximidade entre Jesus e a Samaritana e pode-se destacar, novamente, a hospitalidade que acontece entre eles, bem como a responsabilidade e o cuidado que vai se revelando neste encontro.

Neste cenário, além da figura central personificada por Jesus, encontra-se a mulher Samaritana e tal postura vincula-se ao depoimento de Adélia Prado quando proclama que este segundo lugar, este anonimato, que é o caráter do feminino, tem que renascer para que o mundo respire. As possibilidades de renascimento do mundo são inúmeras, mas dada a proposta de uma caminhada ecopedagógica, estão sendo sugeridos três símbolos que compõem o cenário descrito: o poço, o balde e a água, e tais imagens têm sua razão de ser enquanto apontam para uma realidade, indicam um caminho e sugerem um sentido existencial. 


\subsubsection{O poço}

A indicação do poço, segundo o relato bíblico, ficava na cidade de Sicar, na região da Samaria, local do encontro de Jesus com uma mulher Samaritana. A imagem do poço, além deste episódio, é sempre uma recordação familiar ou comunitária porque o mesmo faz parte destas relações sociais mais próximas. De modo geral temos na memória uma cena na qual o poço se tornou uma alusão à presença de pessoas e esta característica pode transformar-se no pertencimento a um agrupamento social. Assim, a imagem do poço é a referência de que a condição humana exige um pertencimento e reconhecimento entre os humanos e dos agrupamentos sociais.

Numa reflexão sobre esta realidade, Gustavo Gutiérrez lançou um livro com o título: Beber no próprio poço, no qual expressa a importância de acolher a realidade, de perceber a dinâmica das instituições e de compreender as suas condições existenciais. Ao mesmo tempo está sugerindo que o poço tenha uma força para irrigar os laços comunitários, principalmente daqueles que peregrinam na busca de um mundo mais justo e saudável, porque, segundo o autor, “a experiência espiritual é o poço do qual teremos de beber" (1984, p. 151).

Portanto, beber no próprio poço não é um posicionamento narcísico de autocontemplação, mas um exercício cotidiano de mergulhar na profundidade da condição humana e das situações existenciais, e com base nesta percepção jorrar com uma nova energia que possa irrigar o pensamento e o sentimento para uma relação mais cordial com os outros e com o planeta, e possa banhar a dimensão ecológica do ser humano e da natureza.

A caminhada ecopedagógica, tendo como referência a imagem do poço, deveria ser um convite para mergulhar na profundidade dos conhecimentos e perceber, segundo Pena-Vega (2003), que no âmbito de uma ciência ecológica, o que interessa não são os conhecimentos adquiridos e certificados, mas os princípios organizadores que podem proporcionar a diversidade e multiplicidade de conhecimentos, desenvolvendo um pensamento multidimensional, uma ciência transdisciplinar e uma educação ecologizada.

O poço é, portanto, o símbolo da identidade pessoal e comunitária que se vincula à intersubjetividade cultural e coletiva. Nesta relação entre a identidade e a intersubjetividade, o reconhecimento da singularidade e da alteridade torna-se uma característica essencial da identificação humana. Portanto, o percurso pedagógico seria um mergulho no mistério do "eu" e do "outro", configurando, assim, um passo inicial da caminhada ecopedagógica. 


\subsection{2 $\mathrm{O}$ balde}

O diálogo entre Jesus e a mulher Samaritana na cercania do poço, se dá em razão da água, que precisa ser retirada de um poço profundo. A figura do balde remete para a experiência de proximidade entre os dois figurantes, isto é, o cântaro se transformou numa instrumentalidade que proporcionou um diálogo entre eles e, em consequência, uma maior aproximação. É interessante observar que o balde estava vazio, fato que remete à possibilidade de um preenchimento pela presença e proximidade de ambos.

A proximidade pode se dar de distintas maneiras, seja pelo envolvimento pessoal, pelo desenvolvimento de projetos comuns ou pela convivência social. Nesta perspectiva, Paulo Freire afirma que "sua presença se vá tornando convivência, que seu estar no contexto vá virando estar com ele" (1998, p. 85). Percebe-se, portanto, que a instrumentalidade deixa de ser importante na medida em que a presença se transforma em proximidade, ou enquanto a vivência se transforma em convivência.

No contexto da cultura moderna e no espaço educativo o paradigma predominante continua sendo o da dicotomia, da separação e da exclusão. Segundo Pelizzoli (1999), vivemos marcados por uma razão instrumental e por uma egologia hegemônica, aspectos que começam a exigir um paradigma holístico que possa compreender os sistemas como dinâmicas abertas, buscando o equilíbrio entre as forças materiais e espirituais, gerando relações dinâmicas entre a subjetividade e a alteridade, bem como, proporcionando um diálogo constante entre o homem e a natureza.

A caminhada ecopedagógica tem necessidade de instrumentalidades, mas é urgente a superação de um modelo educacional que busca preencher o "balde vazio", isto é, o processo de completar os espaços educativos com um aguaceiro de dados, de informações ou de tecnologias. O procedimento educacional, tendo como referência a ecopedagogia, deveria priorizar uma proposta de proximidade com os conhecimentos já disponibilizados pela humanidade, e despertar para uma consciência criativa e crítica de novos saberes.

$\mathrm{O}$ balde expressa, neste caso, tanto a instrumentalidade quanto a finalidade. $\mathrm{O}$ balde é um instrumento para retirar a água, porém quando está cheio, a finalidade do encontro se materializa. Nesta relação entre a instrumentalidade e a finalidade, a complementaridade e conectividade se transformam num projeto educativo porque articulam a "mediação" da tecnologia e a "intencionalidade" da formação humana. Assim, o percurso pedagógico seria um peregrinar no mistério da natureza humana e do meio ambiente, configurando-se em mais uma pegada desta caminhada ecopedagógica. 


\subsubsection{A água}

O elemento central do relato bíblico está em torno da água que é buscada no poço e retirada por meio de um balde. A mudança mais significativa, porém, está na identificação desta água com Jesus, que se transforma em água que jorra para a vida eterna. Esta água, que é a própria divindade, pode ser buscada na profundidade do coração da humanidade, e na medida em que acolhe a palavra de Cristo e o projeto do seu Reino, a mulher parte em direção ao povoado para anunciar o encontro com o Messias. Segundo Corbí (2010), a grande massa de água, que poderia ser identificada com o Mestre, agora estaria presente na pequena gota, isto é, na vida da mulher Samaritana.

Com o objetivo de criar uma conexão daquela experiência original com o contexto atual é recomendado vincular-se à percepção de Zigmunt Bauman, que procura identificar a dinâmica histórica moderna com a categoria do líquido e cuja sistematização se encontra nas obras que tratam do mundo líquido, da vida líquida, do amor líquido, do tempo líquido. Segundo o autor, "a modernidade líquida não fixa objetivo para si mesma e não traça qualquer linha de chegada; mais precisamente, ela atribui qualidade de permanência apenas ao estado de transitoriedade" (2011, p. 220). Para o cumprimento deste projeto, as habilidades recomendadas são a instantaneidade do tempo, a flexibilidade nas relações e a crescente necessidade de consumo.

Apesar de essa tendência ser majoritária no percurso que a humanidade estaria percorrendo no limiar deste século, começam a aparecer indicadores de que "a modernidade líquida dá sinais de saudade de Deus, da interioridade, da contemplação" (SILVA, 2011, p. 222). Portanto, apesar de se valorizar em excesso a exterioridade do corpo, há uma busca pela interioridade da alma; apesar da dinâmica da vida estar atrelada à competitividade, existem iniciativas que estão promovendo a compaixão; apesar da situação histórica contemporânea estar identificada com o líquido, existe a procura pela fonte da água viva.

A caminhada ecopedagógica, no contexto da água, por um lado é a superação dos modelos educativos demarcados pela disciplina, pela fragmentação e pela disjunção e, por outro, a proposição de um paradigma mais transdisciplinar, sistêmico e holístico. Esta passagem será possível, segundo Leonardo Boff, não apenas com a ciência, mas principalmente com a imaginação, a paixão e a cultura da complexidade, porque "ela nos permite ver as inter-relações de todos com todos e as ecodependências do ser humano" (2012, p. 153). Tal proposta estaria mais próxima da água do que da cisterna, da nascente do que da represa, do fluxo da água do que do refluxo de uma sociedade líquida. 
A água, no cenário descrito, tem o significado de direção e de sentido. A mulher corre em direção ao povoado, mas carrega consigo um novo sentido para a sua existência. Nesta relação entre a "direção" e o "sentido", a dignidade humana configura-se como uma dinâmica educativa. Por isso, o percurso pedagógico seria uma corrida para o mistério da humanidade e da divindade, configurando-se numa pegada essencial nesta caminhada ecopedagógica.

No percurso feito neste exercício reflexivo, tendo como referência uma caminhada ecopedagógica, foi de fundamental importância a compreensão educativa que integra, segundo Síveres (2015), a pedagogia da presença, da proximidade e da partida. Assim, ao aspecto da presença foi vinculada a imagem do poço, da proximidade, a figura do balde e a partida, à representação da água.

Enfim, o processo ecopedagógico é um percurso em direção ao mistério, que pode estar na interioridade da pessoa humana, nas relações sociais ou na vinculação com o sagrado, porém aqui se tentou insistir na conexão do ser humano com o meio ambiente. Esta experiência de integrar o imanente e o transcendente, de articular o interior e o exterior, ou de ressignificar o material e o espiritual requer uma disposição constante de se encontrar no poço, de partilhar as expectativas do balde vazio e de partir em direção a um projeto de vida renovador, aspectos que podem contribuir com uma proposta educativa mais significativa para a sociedade contemporânea.

\section{Conclusão}

A dimensão humana está permeada, além da própria subjetividade, pelas dinâmicas demarcadas pela natureza, pela sociedade e pela divindade. É preciso, portanto, reconhecer e valorizar estas categorias no conjunto de todos os seres e espécies para que se possa buscar, cada vez mais, uma vida com mais qualidade e maior dignidade. Na sequência desta percepção é necessário ampliar a rede de relações para que se estabeleçam, com base em novos relacionamentos, procedimentos para retroalimentar a existência do ser humano e da civilização planetária.

Neste contexto, a mística ecológica precisaria contemplar o desenvolvimento conceitual da cidadania, da democracia, da responsabilidade e da sustentabilidade; promover comportamentos pessoais e coletivos de solidariedade, compaixão, tolerância e respeito; e, fortalecer atitudes de justiça, ética, igualdade e dignidade humana, objetivando gerar relacionamentos pessoais mais amorosos, recriar a esperança na sociabilidade humana e promover o respeito pelo meio ambiente.

Impulsionada por uma mística ecológica, a caminhada ecopedagógica teria 
como pressuposto o sujeito educativo que foi proposto pela figura da mãe, da irmã e da mulher, subjetividades vinculadas às virtudes da hospitalidade, da responsabilidade e do cuidado, respectivamente. A caminhada destes sujeitos deveria ter como sinalizador do caminho um cenário no qual foram indicados os símbolos do poço, do balde e da água, apontando para a necessidade de uma pedagogia da presença, da proximidade e da partida.

Assim, o trabalho sobre a mística ecológica para uma caminhada ecopedagógica, tendo como inspiração o documento do Papa Francisco, poderia ainda se reportar à afirmação de que "Tudo está interligado. Por isso, exige-se uma preocupação pelo meio ambiente, unida ao amor sincero pelos seres humanos e a um compromisso constante com os problemas da sociedade" (2015, p. 60). Além deste posicionamento mais universal, teve-se como fator de criação a entrevista da poetisa Adélia Prado que, além das epígrafes que motivaram esta reflexão, sugere que $a$ arte e a espiritualidade deveriam ser dois braços do mesmo rio.

Os diversos braços que vão compondo o rio expressam, por sua vez, que o contínuo encontro das águas se dá por meio de um abraço. A sinergia dos abraços é que vai se configurando num relacionamento de coexistência e, segundo Capra (2005), no contexto da teoria dos sistemas, a dinâmica da rede estaria presente em todas as formas de vida, destacando-se a importância de um procedimento relacional de cooperação, de parceria e de conectividade, bem como, percebendo a vida como uma energia flexível, cheia de significado e contribuindo para o sentido existencial da condição humana.

A proposta desta reflexão, por meio do exercício de uma mística ecológica para desenvolver uma caminhada ecopedagógico, seria justamente a retomada e a ressignificação da aliança que os seres humanos precisariam realizar consigo mesmos, com os outros e com a transcendência, mas de modo especial com a natureza. A compreensão do conceito e a experiência da aliança estariam superando, assim, o entendimento de um acordo tácito e ultrapassaria a proposta de um contrato social, buscando constituir-se numa energia vital dos sujeitos educativos, que se expressa num compromisso pessoal e numa solidariedade terrenal com as gerações atuais e futuras da humanidade.

\section{Referências}

BAUMAN, Z. A ética é possível num mundo de consumidores? Rio de Janeiro: Jorge Zahar Editor, 2011.

BOFF, L. Ética e moral: a busca dos fundamentos. Petrópolis, RJ: Editora Vozes, 2003. 
Virtudes para um outro mundo possível, vol. I: Hospitalidade: direito e dever de todos. Petrópolis, RJ: Editora Vozes, 2005.

Carta da Terra. In: BOFF, Leonardo. Sustentabilidade: o que é, o que não é. Petrópolis, RJ: Editora Vozes, 2012. p. 167-177.

CAPRA, F. O ponto de mutação: a ciência, a sociedade e a cultura emergente. São Paulo: Editora Cultrix, 2004.

As conexões ocultas: ciência para uma vida sustentável. São Paulo: Editora Cultrix, 2005.

CIRNE, L. F. R. O espaço da coexistência. Uma visão interdisciplinar de ética socioambiental. São Paulo: Edições Loyola, 2013.

CORBÍ, M. Para uma espiritualidade leiga. Sem crenças, sem religiões, sem deuses. São Paulo: Paulus Editora, 2010.

DERRIDA, J. Cosmopolities de touts les pays, encore um effort! Paris: Galilée, 1997.

FREIRE, P. Pedagogia da autonomia: saberes necessários à prática educativa. 9. ed. São Paulo: Paz e Terra, 1998.

GUTIÉRREZ, G. Beber no próprio poço. Itinerário espiritual de um povo. Petrópolis, RJ: Editora Vozes, 1984.

GUTIÉRREZ, F.; PRADO, C. Ecopedagogia e cidadania planetária. 3. ed. São Paulo: Cortez Editora, 2013.

HEIDEGGER, M. Ser e tempo. 7. ed. Petrópolis, RJ: Editora Vozes, 2012

JONAS, H. O princípio responsabilidade: ensaio de uma ética para a civilização tecnológica. Rio de Janeiro: Contraponto Editora; Ed. PUC-Rio, 2006.

KANT, I. À paz perpétua. In: KANT, I. A paz perpétua e outros opúsculos. Lisboa, PT: Edições 70, 1995, p. 119-171. 
LEFF, E. Saber ambiental: sustentabilidade, racionalidade, complexidade, poder. Petrópolis, RJ: Editora Vozes, 2001.

LIMA VAZ, H. C. de. Experiência mística e filosofia na tradição ocidental. 2. ed. São Paulo: Edições Loyola, 2009.

MORIN, E. O método 6: Ética. Porto Alegre: Editora Sulina, 2005.

PAPA FRANCISCO. Carta Encíclica Laudato Si' sobre o cuidado da casa comum. Brasília: Edições CNBB, 2015.

PELIZZOLI, M. L. A emergência do paradigma ecológico: Reflexões ético-filosóficas para o século XXI. Petrópolis, RJ: Editora Vozes, 1999.

PENA-VEGA, A. O despertar ecológico. Edgar Morin e a ecologia complexa. Rio de Janeiro: Editora Garamond, 2003.

SÍVERES, L.; MELO, P. G. R. de. A pedagogia da hospitalidade a partir da filosofia da alteridade em Levinás. In: Conjectura. Filosofia e Educação, v. 7, n. 1 (jan./dez. 2002), Caxias do Sul, RS: EDUCS, 2012, p. 34-48.

Encontros e diálogos. Pedagogia da presença, da proximidade e da partida. Brasília: Liber Livros, 2015.

SILVA, M. P. G. O. da. Educação para a transcendência: palavra e silêncio. In: GUEVARA, Arnoldo José de Hoyos; DIB, Vitória Catarina et al (Org.). Educação para a era da sustentabilidade. São Paulo: Saint Paul Editora, 2011, p. 215-230.

STENGERS, I.; PRIGOGINE, Ilya. A nova aliança: a metamorfose da ciência. Brasília, DF: Editora Universidade de Brasília, 1991.

Recebido em: 10 abril 2016.

Aceito em: 20 abril 2016. 